\title{
Desalination of Sea Water Using Polymer Inclusion Membran (PIM) With Aliquat 336-TBP (Tributhyl Phosphate) as Carrier Compound
}

\author{
Muhammad Cholid Djunaidi ${ }^{1 . *}$. Henry Fauzi $^{1}$. and Rum Hastuti ${ }^{1}$ \\ ${ }^{1}$ Departement Chemistry Faculty Sains and Mathematica Diponegoro University. Indonesia
}

\begin{abstract}
Desalination of Sea Water using Polymer Inclusion Membrane has been done. PIM is known has high stability membrane to overcome the instability of liquid membrane. PIM was placed among two phase : source phases was sea water and feed phases was aquadest. Efficiency of desalination is known by determining salinity concentration and ion $\mathrm{Na}^{+}$in feed phases and stripping phases using refractometer and AAS. while membrane characterization is done using FTIR. SEM and UV-Vis spectroscopy. The PIM membrane that is produced has thin. transparent. clear and flexible properties. The result showed that PIM transport for 24 hours give the highest of salinity transport. there are $92.68 \%$ is transported from feed phases and $84.87 \%$ in stripping phases. Membrane characterization result by FTIR and UV spectroscopy showed that PIM membrane is stable enough.
\end{abstract}

\section{Introduction}

Sea water as a water resource can be utilized to meet clean water needs. Rapid population. industrial growth and expansion led to an increase in water demand. Not to mention the existence of water pollution by industries and households that can reduce the supply of clean water available. With the management of sea water into fresh water and ready-to-drink water. it can increase the supply of clean water needs which has an impact on the reduction of poverty rate and is an important aspect in future industrial development. Good quality water can be met. namely. by processing dirty water into clean water or removing salt from seawater (desalination) [1].

Desalination techniques have long been known and carried out. i.e. distillation (thermal processes) and membrane processes such as reverse osmosis. ion exchange and electrodialysis. The use of liquid membrane offers a new alternative to seawater desalination process. Liquid membrane has attracted the attention of many researchers because of its high selectivity in the presence of carrier substances contained in the membrane. Djunaidi et al (2017) [2] recovered chromium (VI) metal ions from electroplating waste using Supported Liquid Membrane (SLM) with results of more than $60 \%$ chromium transported to the receiving phase using a single carrier compound of Aliquat 336. Applications of liquid membranes for desalination have been widely undertaken. one of which was conducted by Maryati (2008) [3]. The results showed that decreasing salinity level for Aliquat 336 single carrier compound was $96.696 \%$ and for Aliquat $336-$ TBP mixed carrier compounds was $100 \%$. However. their lack of stabilization dissosiates the liquid membrane from applications / commercializations in the process of separating and purifying the industry. This instability is caused by the loss of the solvent and the carrier into the solution caused by the formation of the emulsion droplets or caused by the pressure difference present in the membrane [4]. Liquid membranes commonly used are supported liquid membrane. emulsion liquid membrane (ELM) and bulk liquid membrane (BLM). Nevertheless. the they still have weaknesses: BLM has interface surface area and low mass transfer rate. while the breakage of emulsion is a problem in ELM. SLM has major weakness in low stability. this weakness is also owned by ELM and BLM [5].

In order to overcome these problems. Sugira et al. (1987) [6] managed to obtain a stable membrane. by entangling the liquid membrane into the cellulose acetate membrane added with plasticizer. which became a new generation of Supported Liquid Membrane. This type of facilitated transport membrane is called Polymer Inclusion Membrane (PIM). PIM shows the advantages than other liquid membranes especially SLM. This type of membrane is very high stability. lost carrier during process can be ignored. more efficient carrier used. higher flux and more versatile [4.7].

Djunaidi. et al (2017) [8] used PIM with AliquatTBP carrier compound (4: 1) for the recovery of Cr (VI)

\footnotetext{
* Corresponding author: choliddjunaidi@live.undip.ac.id
} 
ions from electroplating waste and the result was good. The Cr (VI) ions transferred from the feed phase was $99.24 \%$ and the transferred in the receiving phase was $85.88 \%$.

Looking at the advantages of PIM as mentioned previously. in this research. desalination was conducted by using PIM. In this study. PIM used consisted of Aliquat 336-TBP carrier compound. tetrahydrofuran (THF) as solvent. dibutylether (DBE) as plasticizer and PVC as base polymer. The mixture of Aliquat and TBP carrier compounds provided synergistic effect in extracting $\mathrm{ZrCl}_{6}{ }^{-2}$ [9] and $\mathrm{HCrO}_{4}^{-}$[10]. PIM performance was influenced by membrane surface area (membrane thickness). feed phase concentration. and $n$ times of the use of membrane. Therefore. in this research variations of those parameters were considered to determine the effect on salinity transport process occuring in both feed and receiving phases. The solution used in the feed phase was sea water while the receiving phase was aquadest.

\section{Experimental Method}

\subsection{Instruments}

A set of PIM tool cells. glassware laboratory. glass print (petridish with diameter 9.5. 11.5 and $13.5 \mathrm{~cm}$ ). analysis scale. Refractomter H-UR-201. AAS (Atomic Absorption Spectroscopy). FTIR and UV- Vis spectroscopy. Scanning Electron Microscope (SEM).

\subsection{Material.}

Sea Water was taken from Logending Beach Cilacap, aqua deminiralisated (Bratachem), and chemicals were bought from Sigma Aldrich i.e polyvinyl chloride (PVC), Aliquat 336, TBP, dibutyleter (DBE) and THF.

\subsection{Experimental Procedures}

\subsubsection{Membrane Fabrication}

A set of PIM tool cells. glassware laboratory. glass print (petridish with diameter 9.5. 11.5 and $13.5 \mathrm{~cm}$ ). analysis scale. Refractomter H-UR-201. AAS (Atomic Absorption Spectroscopy). FTIR and UV- Vis spectroscopy. Scanning Electron Microscope (SEM).

\subsubsection{Sea Water Desalination using PIM Feeding Phase (FP) Solution Preparation}

The feed solution used was seawater with dilution of 100. 50 and 10 times.

\subsubsection{Preparation of the Receiving Phase (FP) Solution}

The receptor solution preparation used in the process was aquadest

\section{Results and Discussion}

This research was conducted for desalination of seawater using Polymer Inclusion Membrane (PIM).

\subsection{Fabrication of Polymer Inclusion Membrane (PIM)}

Polymer Inclusion Membrane (PIM) was produced by mixing PIM components consisting of PVC (polyvinyl chloride) base polymer. Aliquat 336:TBP (4: 1) as carrier compounds and DBE (dibutylether) as plasticizers dissolved in THF solvent to produce PIM membrane thin. clear. non-fragile and effectively capable of desalination.

\subsection{Membrane Characterisation before Use}

\subsubsection{FTIR spectra analysis}

The determination of active groups of resulting PIM membrane was done using FTIR spectrophotometer. The result of membrane analysis before stirring is shown in the figure 1 below:

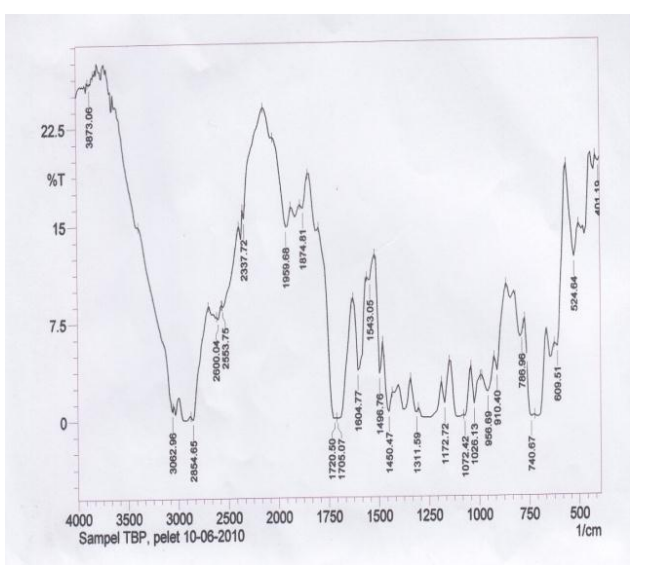

Fig. 1. FTIR Spectrum of the PIM membrane prior to stirring

The FTIR spectrum of membrane prior to stirring showed a sharp absorption band in the $3062.96 \mathrm{~cm}^{-1}$ region indicating the presence of an unsaturated $\mathrm{CH}$ (=CH-) group. $2854.65 \mathrm{~cm}^{-1}$ showing the presence of an alkyl group $\left(-\mathrm{CH}_{3}\right)$ reinforced by the band at 1311.59 $\mathrm{cm}^{-1}$ and $1450.47 \mathrm{~cm}^{-1}$. In the meantime. the absorption at $1720.5 \mathrm{~cm}^{-1}$ region shows the carbonyl group $(\mathrm{C}=\mathrm{O})$. the absorption band at $1026.13 \mathrm{~cm}^{-1}$ region indicates the presence of ether (CO). absorption at $910.4 \mathrm{~cm}^{-1}$ assigns to the presence of an alkyl $\mathrm{CH}_{2}$ group. absorption band at $740.67 \mathrm{~cm}^{-1}$ produced a series of methylene. while vibration mode at $609.51 \mathrm{~cm}^{-1}$ indicated the presence of $\mathrm{C}-\mathrm{Cl}$ group [11]. This results confirm that there are 
compounds of PIM membrane constituent components in the membrane.

\subsubsection{Scanning Electron Microscopy (SEM) Analysis}

The surface morphology and cross section thickness of PIM membrane with Aliquat 336-TBP carrier compounds can be identified by SEM analysis (Scanning Electron Microscopy). Results of SEM analysis of Aliquat 336-TBP membrane are presented in the following figure (2):

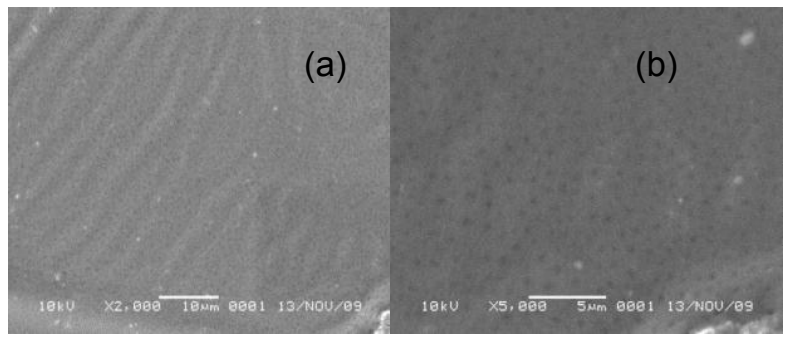

Fig 2. Morphological images of the PIM membrane,

(a) the surface of membrane with the 2000x magnification,

(b) surface of membrane with the 5000x magnification

Analysis of membrane using Scanning Electron Microscopy (SEM) (Fig. 2) shows that surface morphology of PIM membrane with 5000x magnification is not porous. Non-porous PIM membrane can be used to salinity transport occured by diffusion through an intermediate of Aliquat 336-TBP carrier compound (4: 1) [12].

\subsection{PIM Membrane Transport Mechanism}

The salinity transport process took placed through several stages. Initially the saline diffused into the membrane-feed phase interface. then binding to the carrier compound to form ion pair. In this case the carrier compound used was Aliquat 336-TBP. The reactions occuring in sea water desalination can be written as follows [12]:

$$
\begin{aligned}
& \mathrm{nR}_{4} \mathrm{~N}^{+} \mathrm{Cl}^{-}{ }_{\text {mem }}+\mathrm{OH}^{-} \\
& \left(\mathrm{R}_{4} \mathrm{~N}^{+} \cdot \mathrm{OH}^{-}\right)_{\mathrm{n}}+\mathrm{Cl}^{-} \text {aq } \\
& \leftrightarrow\left(\mathrm{R}_{4} \mathrm{~N}^{+} . \mathrm{OH}^{-}\right)_{\mathrm{n}}+\mathrm{Cl}_{\mathrm{mem}} \\
& \left.\leftrightarrow\left(\mathrm{R}_{4} \mathrm{~N}^{+} . \mathrm{Cl}^{-}\right)_{\mathrm{aq}}\right)_{\mathrm{n}}+\mathrm{OH}^{-} \\
& \left(\mathrm{R}_{4} \mathrm{~N}^{+} \cdot \mathrm{Cl}^{-}{ }_{\mathrm{aq}}\right)_{\mathrm{n}}+\mathrm{nTBP} \\
& \leftrightarrow \mathrm{n}\left(\mathrm{R}_{4} \mathrm{~N}^{+} \cdot \mathrm{Cl}^{-}{ }^{-} \mathrm{q}\right) \cdot \mathrm{nTBP} \\
& \mathrm{n}\left(\mathrm{R}_{4} \mathrm{~N}^{+} . \mathrm{Cl}^{-}{ }_{\mathrm{aq}} \cdot \mathrm{TBP}\right)+\mathrm{OH}^{-} \leftrightarrow \mathrm{n}\left(\mathrm{R}_{4} \mathrm{~N}^{+} . \mathrm{OH}^{-}\right)+\mathrm{TBP}+\mathrm{Cl}^{-}{ }_{\mathrm{aq}}
\end{aligned}
$$

The Aliquat-Cl-ion pair diffused to the membranereceptor phase interface. In the membrane-receptor phase interface. the Aliquat-Cl- ion pair will be solvated by the TBP carrier compound so that $\mathrm{Cl}^{-}$would be released and was exchanged with $\mathrm{OH}^{-}$in the receiving phase. This process was continuous and reversible.

\subsection{Effect of Feed Phase Concentration}

In the feed phase. concentration variation of $10 x .50 x$ and 100x samples dilution was used in membrane $\mathrm{B}$ and stirring had been conducted for 24 hours. Results obtained as follows (table 1):

Table 1. Effect of variation of sample concentration on $\%$ desalination

\begin{tabular}{|c|c|c|}
\hline $\begin{array}{c}\text { Variation } \\
\text { concentration } \\
\text { (dilution) }\end{array}$ & $\begin{array}{c}\text { \% desalination in } \\
\text { FP }\end{array}$ & $\begin{array}{c}\text { \% Desalination in } \\
\text { RP }\end{array}$ \\
\hline $10 \mathrm{x}$ & 50.24 & 36.58 \\
\hline $50 \mathrm{x}$ & 72.13 & 57.37 \\
\hline $100 \mathrm{x}$ & 74.19 & 58.06 \\
\hline
\end{tabular}

Table 1 shows that salinity transport at 100x dilution using Aliquat-TBP membrane shows a large percentage of desalination. whereas the increasing concentration of seawater samples at 50x and 10x dilutions indicates the decrease of desalination percentage in the receiving phase. This is due to the greater the concentration of feed phase causes the lower the salinity transported from the feed phase to the receiving phase. The ability of membrane performance decreased. the greater the concentration of the sample. the stronger the intermolecular force causing the difficulty of salinity transport through the membrane to the receiving phase.

\subsection{Effect of Membrane Thickness}

The thickness of membrane was varied by varying the diameter of petridish membrane. namely. $9.5 \mathrm{~cm} .11 .5$ $\mathrm{cm}$ and $13.5 \mathrm{~cm}$. Results obtained as follows (table 2).

Table 2. Effect of membrane thickness variation on \% desalination

\begin{tabular}{|c|c|c|}
\hline $\begin{array}{c}\text { Variation of } \\
\text { Membrane } \\
\text { Thickness }(\mu \mathrm{m})\end{array}$ & $\begin{array}{c}\text { \% Desalination } \\
\text { in }\end{array}$ & $\begin{array}{c}\text { \% Desalination } \\
\text { in } \\
\text { FP }\end{array}$ \\
\hline $25(9.5 \mathrm{~cm})$ & 50.24 & 36.58 \\
\hline $20(11.5 \mathrm{~cm})$ & 83.34 & 75.60 \\
\hline $10(13.5 \mathrm{~cm})$ & 92.68 & 84.87 \\
\hline
\end{tabular}

Table 2 shows that the thinner the membrane (the larger the diameter of the membrane) the more percentage of desalination in the feed phase and the better the transport to the receiving phase. Conversely. the thicker the membrane the less salinity transported to the receiving phase because the diffusion rate was slower. This can be explained by Fick law $\mathrm{J}=-\mathrm{D} d \mathrm{dc} / \mathrm{dx}$ stating that the diffusion rate is inversely proportional to the thickness of the interphaselayer/flux distance [13]. From this equation it can be seen that the thicker the membrane the longer the flux distance traveled by the Aliquat-TBP ion pair with salinity to get to the receiving phase which causes the low diffusion rate so that the percentage of desalination to the receiving phase was reduced. Other researchers [8] experienced the same thing in transporting $\mathrm{Cr}(\mathrm{VI})$.

\subsection{Influence $\mathbf{n}$ Membrane Usage}

In Aliquat 336-TBP membrane for $\mathrm{n}$ times use with $3 \mathrm{x}$ membrane use. the following data were obtained: 
Table 3. Effect of $\mathrm{n}$ times the use of membrane on $\%$ desalination

\begin{tabular}{|c|c|c|}
\hline $\begin{array}{c}\text { Variation of } n \\
\text { times of } \\
\text { Membrane use }\end{array}$ & $\%$ Transport in FP & \% Transpor in RP \\
\hline 1 & 87.87 & 84.94 \\
\hline 2 & 83.40 & 84.81 \\
\hline 3 & 78.94 & 55.01 \\
\hline
\end{tabular}

As seen in Table 3 it can be concluded that there is decrease in membrane transport capacity (as seen from the decreasing percentage of desalination in the feed phase) due to the use of membrane $n$ times as well as the decreasing percentage of desalination in the receiving phase. This indicates decrease in the ability of the membrane to be used more than 1 times the use. This is likely due to the closed surface of the membrane after the stirring of white flakes prevented the transport of salinity to the receiving phase.

\subsection{Use of Blank Membranes}

The making of a blank membrane without a carrier compound is performed as a comparison of the PIM membrane with the Aliquat 336-TBP carrier compound. Desalination using a blank membrane with stirring for 24 hours shows a desalination percentage of 0 (no metal transport) either from the feed phase or the receiving phase. this is due to the absence of the carrier compound in the blank membrane. From these results it can be concluded that salinity transportability occurs due to the role of carrier compounds in the membrane.

\subsection{Sodium Ion Transport}

In addition to transporting $\mathrm{Cl}^{-}$(salinity). the mixed Aliquat-TBP compound carrier also transported the content of the main constituent cations of salinity. especially sodium $\left(\mathrm{Na}^{+}\right)$ions. This was likely to occur because of the role of the TBP carrier compound as well as the neutralizing reaction resulting from the transfer of $\mathrm{Cl}^{-}$ions into the receiving phase [12]. The amount of sodium ion transported from the feed phase can be seen in the table below.

Table 4 shows that $\mathrm{Na}^{+}$ions contained in seawater were also transferred from the feed phase to the receiving phase in the transport process of sea water salinity. Based on this result. it can be seen also that the use of membrane with thickness of $10 \mu \mathrm{m}$ in the feed phase. sodium ion transported was $96.89 \%$ whereas in the receiving phase. the sodium ion transported was $38.57 \%$.
Table 4. Sodium content transported at feed phase and receiving phase after stirring for seawater using AAS analysis

\begin{tabular}{|c|c|c|}
\hline \multicolumn{2}{|c|}{ Thickness of Membrane $(\mu \mathrm{m})$} & 10 \\
\hline \multirow{2}{*}{$\begin{array}{l}\text { Concentration of } \mathrm{Na}^{+} \\
\text {before desalination } \\
(\mathrm{ppm})\end{array}$} & Feed Phase & 109,400 \\
\hline & $\begin{array}{c}\text { Receiving } \\
\text { Phase }\end{array}$ & 0 \\
\hline \multirow{2}{*}{$\begin{array}{l}\text { Concentration of } \mathrm{Na}^{+} \\
\text {after desalination } \\
(\mathrm{ppm})\end{array}$} & Feed Phase & 3,400 \\
\hline & $\begin{array}{l}\text { Receiving } \\
\text { Phase }\end{array}$ & 42,200 \\
\hline \multicolumn{2}{|c|}{$\begin{array}{l}\mathrm{Na}^{+} \text {level } \\
\text { Transported from feed phase } \\
(\%)\end{array}$} & 96.89 \\
\hline \multirow{2}{*}{$\begin{array}{l}\mathrm{Na}^{+} \text {level } \\
\text { Transported to } \\
\text { receiving phase } \\
(\%)\end{array}$} & Feed Phase & \multirow[t]{2}{*}{38.57} \\
\hline & $\begin{array}{l}\text { Receiving } \\
\text { Phase }\end{array}$ & \\
\hline
\end{tabular}

\subsection{Membrane Characterization after Stirring}

\subsubsection{FTIR spectra analysis}

FTIR analysis on the PIM membrane after the stirring process is used to determine the presence of functional groups possible missing from the membrane.

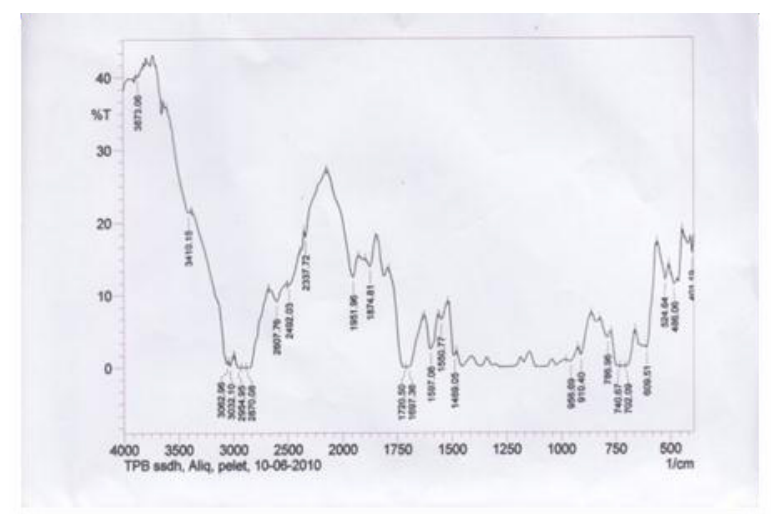

Fig 3. FTIR spectrum of PIM membrane after stirring

FTIR spectrum of PIM membrane after stirring (Fig 3) shows the same spectrum of PIM membrane before strirring in which compounds of constituent components of PIM membrane were present. The peak shift that occured may be the effect of ion pair formation happening between salinity and the Aliquat-TBP carrier compound taking place on the membrane.

\subsubsection{Stability Analysis of PIM Membrane}

In order to determine the PIM membrane stability. UV-Vis analysis was performed on the membranes. feed and receiving phases before and after stirring in seawater desalination process. Membrane stability is indicated by the absence of organic compounds both in the feed phase 
and the receiving phase shown in the UV-Vis spectrum (Fig 4-5). Analysis of membrane using UV-Vis spectrophotometer resulted in the following datum:

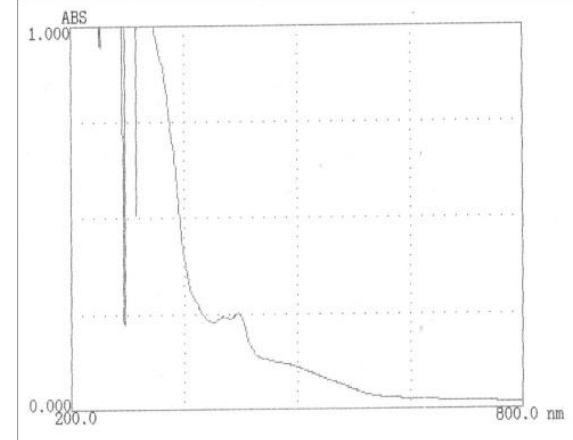

Fig 4. UV-Vis spectrum of feed phase before stirring

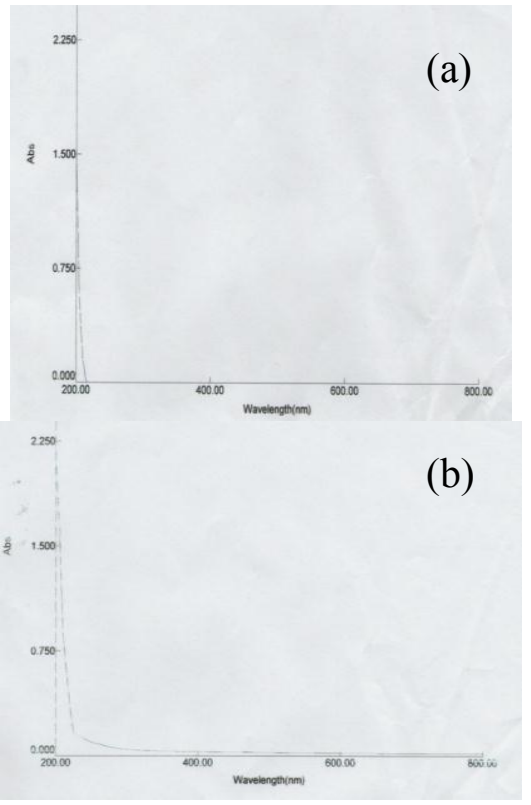

Fig 5. UV-Vis spectrum of feed phase
(a) before stirring
(b) after stirring

The UV-Vis spectrum of the feed phase before and after the stirring (Fig 5) did not show any peak assigned to organic compounds which are constituents of membrane. While the UV-Vis spectrum of the receiving phase after stirring is as follows (Fig 6):

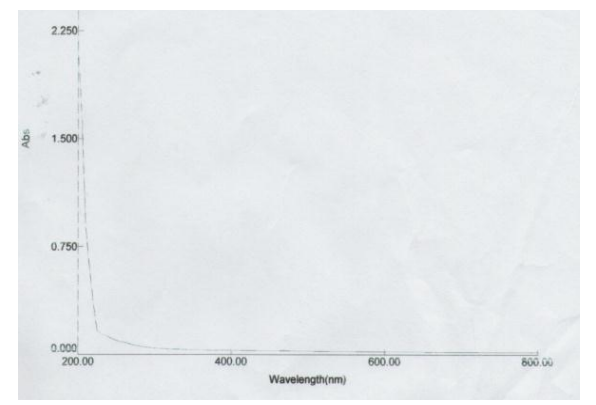

Fig 6. UV-Vis spectrum of the receiving phase after stirring
The above UV-Vis spectrum (Fig 6) shows no new peak of the organic compounds of membrane constutuents. This result proved that there was no organic compound of PIM membrane constituent that dissolved in the feed and the receiving phases. so it can be concluded that the PIM membrane used was quite stable.

\section{CONCLUSION}

Based on the above discussion it can be concluded that PIM membrane was produced with the preoperties: thin. clear. and flexible so that PIM method can be used for desalination of sea water. The highest salinity transport process from the feed phase was $92.68 \%$ and the transport at the receiving phase was $84.87 \%$. The results of membrane characterisation using FTIR and UV-Vis spectroscopy confirmed that the PIM membrane was quite stable.

\section{REFERENCES}

1. W. A. Wardana.. Impact of pollution of Environmental. (Andi. Yogyakarta 2004)

2. M. C. Djunaidi. Khabibi. R. Nurfitriana. R.. Alchemy Jurnal Penelitian Kimia. 13. 119-132 (2017)

3. Maryati.. Supported Liquid membrane (SLM) With Anionic Carrier for Desalination Sea Water. Thesis. Diponegoro University Semarang (2008)

4. S. Kusumocahyo. K. Sumarua. T. Iwatsubo. T. Shinbo. T. Kanamori. H. Matsuyamab and M. Teramoto. J. Membr. Sci. 350 143-152 (2006)

5. L. Nghiem. M. Patrick M.. D. Ian . M. Jilska. Perera. W. Robert . Cattrall. and S. Kolev.. J. Membr. Sci. 281 (2006) 7-41 (2006)

6. M. Sugira. M. Kikkawa. and S. Urita. J. Membr. Sci. 42. 47-55 (1989)

7. J. Gardner. P. Quinn. O. Jedediah. Walker. D. Bryce. . A. Bibhutosh. G. Roger and J. Lamb. J. Membr. Sci. 121 (9) 103-107 (2005)

8. M. Cholid Djunaidi. R. Ariadi Lusiana. M. damayanti Rahayu. The 2nd International Conference on Materials Engineering and Nanotechnology IOP Publishing IOP Conf. Series (2017)

9. B. M. Misra. Supported Liquid Membranes in Metal Separation. C.S. Symposium Series 642. Chemical Separation with Liquid Membrane. American Chemical Society; Washington. pp 361-375 (1996)

10. M. Rahayu. D. Separation of Cr(VI) using Supported Liquid membrane. Thesis (2009)

11. H. Sastrohamidjojo. Spektroskopi. Liberty. Yogyakarta (2001).

12. S. M. Khopkar. Basic Concept of Analytical Chemistry. Penerbit UI. Jakarta (1990)

13. M. Mulder. Basic Principles of Membrane Technology. Kluwer Academic Publisher. London. 10-12 (1996) 